\title{
The Downward Trend in Postsecondary Horticulture Program Availability between 1997 and 2017
}

\author{
Alyssa J. Brown ${ }^{1}$, Phil S. Allen, Greg V. Jolley, and \\ J. Ryan Stewart
}

AdDitional INDEX wORDs. education, decrease, degree, certificate, institution

SuMMARY. For the past several years, many college horticulture programs have experienced a decline in undergraduate enrollment, resulting in the elimination of some degrees. In this study, we compared postsecondary U.S. horticulture program availability from a survey completed in 1997 with offerings existing in 2012 and 2017. In 1997, 446 U.S. postsecondary institutions offered degrees and/or certificates in horticulture. In 2012, this number had decreased by $43 \%$ to 253 institutions, which included 98 with 4 -year degrees, 215 with 2 -year degrees, and 138 with certificate programs. In 2017, the total number of institutions offering horticulture-related degrees and/or certificates decreased to 209, representing a $53 \%$ decrease over the 20 years from 1997 to 2017 and a $17 \%$ decrease during the 5 -year period between 2012 and 2017. In 2017, 85 institutions offered 4-year degrees, 133 offered 2-year degrees, and 98 offered certificate programs, which over this 5 -year period represents decreases of $13 \%, 38 \%$, and $29 \%$, respectively. "Horticulture" was the most common program title in both 2012 and 2017, and the percentage of programs with this name increased during the 5-year period for all program types. In 2017, 28 horticulture programs not identified in the 1997 survey were found, but only two of these were confirmed to have been created since 1997. Overall, these data suggest a trajectory toward elimination of 2 -year and certificate programs, and continued consolidation for 4-year degrees. If it continues, this trend is not favorable for the continued vitality of postsecondary horticulture programs in the United States and may impact progress negatively for the field of horticulture as a whole.

$\mathrm{C}$ ollege horticulture programs face a number of threats, including declining enrollment in both 2 - and 4-year programs, reduced budgets, loss of identity through mergers and consolidations, a perceived low regard for the discipline of horticulture in the wider field of biologic sciences, and negative press in print and online media (Bradley et al., 2003; Higgins, 2018; Loose, 2012; Meyer et al., 2016; Reed et al., 2016; Smith, 2001, 2014). Failure to address these challenges effectively could result in decreased resource allocation, replacement of retiring full-time faculty with adjunct instructors, loss of

Received for publication 18 Dec. 2018. Accepted for publication 7 May 2019

Published online 20 June 2019.

Department of Plant and Wildlife Sciences, Brigham Young University, Provo, UT 84602

${ }^{1}$ Corresponding author. E-mail: alyssajoybrown@ gmail.com.

This is an open access article distributed under the CC BY-NC-ND license (https://creativecommons.org/ licenses/by-nc-nd/4.0/).

https://doi.org/10.21273/HORTTECH04251-18 full-time faculty positions, reduced course offerings, and even elimination of entire programs (Hughes, 2001; LaWell, 2011; Reed et al., 2016; Smith, 2001). During the past two decades, several reports have identified creative responses to these challenges, which include a shift in focus toward making programs more attractive to an increasingly urban student demographic, active marketing campaigns, and leveraging industry partnerships (Bradley et al., 2000; LaWell, 2011; Meyer et al., 2016; Miller, 2011; Reed et al., 2016; Smith, 2001). Although a recent summary of declining enrollment trends in horticulture is available (Reed et al., 2016), and anecdotal evidence suggests that threats to college horticulture programs continue, the lack of data on the number of programs through time has made it difficult to draw meaningful conclusions regarding the viability of postsecondary horticulture offerings at U.S. institutions.

In 2009, we became aware of a previously unpublished 1997 survey that attempted to identify all colleges in the United States that offered certificate, and 2-year and/or 4-year degrees in horticulture. This survey was led by Kent Hammond, Associate Professor of Landscape Contracting, at The Ohio State University Agricultural and Technical Institute. Hereafter referred to as the "1997 survey," this effort resulted in a comprehensive list of institutions that offered one or more 2 -year and/or 4-year degrees in horticulture at that time. The 1997 survey identified 446 postsecondary institutions that offered horticulturerelated programs across the United States. Included in this total were 49 landscape architecture programs. In addition, turfgrass science and, in some cases, agriculture were also included. The survey attempted to capture all horticulture programs, not just programs focused on ornamental horticulture. It is therefore not surprising that his group found a much greater number of postsecondary programs than the 114 colleges and universities offering horticulture programs identified by the American Society for Horticultural Science [unpublished data; cited in Bradley et al. (2000)], which was completed around the same time.

The 1997 survey provided a basis for identifying and quantifying trends in availability of postsecondary horticulture programs in the United States. The primary objective of our study was to determine which institutions from the 1997 survey continued to offer horticulture programs in 2012 and again in 2017. For both years, we identified whether each institution offered certificates, 2 -year, and/or 4-year degrees to better clarify recent trends related to horticulture offerings under each category. We also identified the most common program titles in 2012 and 2017. In 2017, we found additional postsecondary institutions offering horticulture that were not included in the 1997 survey.

\section{Materials and methods}

Hammond 1997 survey. The 1997 survey was based on an earlier list of institutions offering horticulture programs compiled by the Associated Landscape Contractors of America [ALCA (now the National Association of Landscape Professionals)]. Using the ALCA survey as 
a starting point, Hammond's team cross-checked all programs they identified with The College Blue Book (Macmillan Reference USA, 1997). State nursery and landscape trade association executives were contacted to verify that the colleges and universities identified actually offered degrees in horticulture. These executives also helped identify additional programs that may have been missed (K. Hammond, personal communication). In states without landscape-related trade associations, Hammond's team contacted at least one ALCA member to verify and/or identify the existence of horticulturerelated programs. This survey was used as a basis for the research presented in our study.

2012 AND 2017 sURVEYs. Between Oct. 2011 and Apr. 2012, we conducted an Internet survey of all websites of postsecondary institutions reported in the 1997 survey. In 2012, we searched the course catalog of each institution listed, found a listing of the programs available, and reviewed the curriculum of all horticulture-related offerings. We defined a horticulture program as any certificate, 2-year degree, or 4-year degree that included a minimum of three required horticulture classes (e.g., plant identification, plant propagation, nursery management, floral classes) as identified in the online course catalog of the institution. Therefore, some programs including terms in titles such as "agriculture" or "plant science" were counted, whereas others with these same terms were not.

We identified every named horticulture-related degree and defined the type of degree offered for each institution. However, because of the wide variety of subdivisions within degrees, we chose not to include more detail (e.g., "tracks," "specializations," or "emphases"). When the website of an institution included no horticulture program in 2012, we made contact by e-mail and/or phone to verify whether a previously existing horticulture program had been eliminated.

In 2017, we repeated the Internet survey of postsecondary horticulture programs. Again, using the 1997 survey as a starting point, we verified the existence of programs at all listed institutions. In addition to verifying the status of programs in the 2012 survey, this allowed us to determine whether any institutions not offering a program in 2012 had revived it between completion of the 2012 and 2017 surveys. No such programs were found. We also completed a separate Internet search to determine whether new programs had been created since the completion of the 1997 survey. We searched for horticulture programs by state using online lists (Cappex, 2009; Macmillan Reference USA, 1997; Seed Your Future, 2016) and the online database CollegeSource (CollegeSource, 2005) that accesses the course catalogs of postsecondary institutions throughout the United States. Then, we crossreferenced these lists against the 1997 survey. All additional institutions were researched to verify that their relevant programs met the requirement of having three horticulture classes. We listed these additional institutions and programs. Because these additional programs were not included in the 1997 survey, a summary of findings about these institutions is provided here, but they are not represented in comparisons of data and trends regarding the 1997 , 2012 , and 2017 surveys.

\section{Results and discussion}

To the extent the 1997 survey accurately identified postsecondary U.S. institutions offering horticulture degrees, half the institutions had eliminated their horticulture programs 20 years later (Table 1). Compared with $1997,43 \%$ of institutions had eliminated their horticulture degrees by 2012 and $53 \%$ by 2017 . In the 5-year period between 2012 and 2017, the greatest reduction in institutions offering degrees occurred with 2-year programs (38\% decline during this 5 -year period), followed by certificates $(29 \%$ decline $)$ and 4-year degrees (13\% decline).

The 1997 survey used extensive personal contacts to identify colleges and universities offering degrees in horticulture at that time. Possible errors with this approach include false positives (i.e., when contacts reported erroneously that an institution offered a horticulture degree) and false negatives (i.e., when contacts were not aware of a college offering a horticulture degree). However, by searching College Blue Books independently (Macmillan Reference USA, 1997) both types of errors were minimized. Through conversations with Kent Hammond, who led the 1997 survey, we were unable to rule out completely the possibility that horticulture-related degrees (e.g., plant science, agronomy) with no or minimal horticulture were included occasionally (K. Hammond, personal communication). The 1997 survey probably had a small amount of error; however, it represented the most complete and accurate known data set characterizing the status of horticulture education at that time.

In 2012, we were interested initially in capturing enrollment data for horticulture programs. However, we found the information provided was often either unreliable or unavailable. This was particularly true of certificate and 2-year-degree programs. Students attending many institutions offering these programs were working professionals who enrolled part-time and/or only occasionally. For 2-year institutions offering certificates in addition to degrees, it was often unclear

Table 1. Number of U.S. postsecondary institutions offering horticulturerelated 4-year degrees, 2-year degrees, and certificates over a 20 -year period. The 1997 survey did not distinguish between the three program types, but it did identify the total number of schools that offered programs. The 2012 and 2017 surveys quantified the number of institutions offering each type of existing program in addition to how many schools offered any type of horticulture degree.

\begin{tabular}{lccc}
\hline & \multicolumn{3}{c}{ Schools offering horticulture programs (no.) } \\
\cline { 2 - 4 } Program type & $\mathbf{1 9 9 7}$ & $\mathbf{2 0 1 2}$ & $\mathbf{2 0 1 7}$ \\
\hline 4-year degree & - & 98 & 85 \\
2-year degree & - & 215 & 133 \\
Certificate & - & 138 & 98 \\
Total schools & 446 & $253^{\mathrm{z}}$ & $209^{\mathrm{z}}$
\end{tabular}

${ }^{\mathrm{z} B e c a u s e}$ some schools offered multiple types of degree programs, the number of total schools is less than the sum for each type of program. 
whether a particular student had transitioned to a degree program. Because enrollment numbers were frequently acknowledged to be estimates, we chose not to report them here. However, Reed et al. (2016) reported recent horticulture enrollment trends.

We did not include, but recognize the value of, programs offered outside of traditional postsecondary institutions, such as the Professional Gardener Program at Longwood Gardens (B. Trader, personal communication). The 1997 survey was conducted primarily to provide ALCA members with a list of institutions where students interested in landscape-related careers could be recruited (K. Hammond, personal communication). Therefore, landscape architecture programs were included in that survey. We recognize many professionals do not consider landscape architecture to be part of the academic discipline of horticulture. However, similar to other named degrees, we chose to include landscape architecture if the program required a minimum of three horticulture courses. We acknowledge this low-threshold requirement for horticulture inclusion in our survey captures a wide range of programs.

The 2012 and 2017 surveys disfered 2-year and/or 4-year degrees as well as any type of horticulture certificates. As several institutions offered more than one horticulture-related degree, the number of degrees offered was greater (Table 2 ) than the number of institutions offering these degrees (Table 1 ). We found that, similar to the total number of institutions offering horticulture degrees, the number of programs within each category also decreased. Between 2012 and 2017, the overall number of 4-year degrees offered decreased by $54 \%$, which is five times greater than the reduction in the number of tinguished whether institutions of-

institutions offering 4-year degrees (Tables 1 and 2). This sharp decrease resulted from a recent major effort to consolidate (e.g., combine two or more degrees into a single degree that may or may not have parts of both degree names) or to eliminate some degrees. Consolidation was generally evident by comparing the names of degrees offered in 2012 with those in 2017; however, it was at times difficult to determine definitively whether a degree had been eliminated or whether it had been merged with one or more other degrees.

Likely factors associated with the merging and elimination of horticulture degrees include declining enrollment in some formerly popular areas within this field (Reed et al., 2016) as well as efforts to reduce the administrative burden associated with a degree (e.g., resulting from separate assessment requirements for each degree offered). We acknowledge that program consolidation resulting in titles substantially different from traditional horticulture terms could lead to occasional false negatives, especially in cases when the institution's website and course offerings were unclear or difficult to navigate. However, we attempted to minimize these potential errors by searching through the entire list of programs offered at the institutions and reviewing the curriculum of any potentially relevant program to determine whether it met the three-class requirement.

The $38 \%$ reduction in 2 -year degrees offered (calculated from Table 2 ) was coincidentally identical to the percentage reduction in the number of institutions that offered 2-year degrees (Table 1$)$. The percentage decrease in certificates between 2012 and 2017 was less than the decrease in number of institutions that offered certificates $(20 \%)$. This result is in part because of some institutions eliminating their 2-year degrees between 2012 and 2017 , but

Table 2. Number of 4-year degrees, 2-year degrees, and certificate horticulture programs offered at postsecondary U.S. institutions in 2012 and 2017.

\begin{tabular}{lcc}
\hline & \multicolumn{2}{c}{ Horticulture programs offered (no.) } \\
\cline { 2 - 3 } Program type & $\mathbf{2 0 1 2}$ & $\mathbf{2 0 1 7}$ \\
\hline 4-year degree & 344 & 158 \\
2-year degree & 355 & 218 \\
Certificates & 330 & 265 \\
Total programs & 1,029 & 641 \\
\hline
\end{tabular}

continuing or beginning to offer one or more horticulture-related certificates.

Program titles offer clues into the ways institutions market their horticulture curricula. A comparison between the most common words used in 2012 program titles with their use in 2017 indicates that "horticulture" continued to be the most common word associated with horticulture programs. Observed reductions in both institutions and named degrees between 2012 and 2017 did not result in dramatic shifts in program titles. Occurrences of the word "horticulture" actually increased for 4-year degree and certificate categories, despite the declining number of programs. "Landscape" was clearly a popular word in program titles as well. This was partly a result of its frequent association with each of the other commonly used program words in Table 3 (e.g., landscape design, landscape horticulture, landscape management, landscape technology).

Despite title changes and mergers with other programs [and departments (Reed et al., 2016)], "horticulture" as a program title continued to be the most common name for 4-year, 2-year, and certificate programs (Table 4). For 4-year-degree programs, the second most common term was "landscape architecture." However, there was a reduction of more than $50 \%$ in the number of programs titled "landscape architecture" between 2012 and 2017, resulting from several landscape architecture programs falling below the minimum requirement for horticulture classes. The second-most commonly occurring name for 2 -year degrees was "horticulture technology" in both years, whereas the second-most commonly occurring name for certificates was "landscape design" in both years surveyed.

The study of the most common words and titles did reflect some changes between 2012 and 2017 . "Technology" increased in number for 4-year institutions and certificate programs, and as a percentage for all three program types. However, use of the word "turf" decreased in both number and percentage between 2012 and 2017 (Table 3 ) by more than $50 \%$ in both 2 -year and 4 -year degrees. The percentage of 2 -year and certificate programs including the 
Table 3. The six most commonly used words in horticulture degree titles and their frequency of occurrence, and as a percentage of program names in that category (4-year, 2-year, or certificate) between 2012 and 2017.

\begin{tabular}{|c|c|c|c|c|c|c|c|c|c|c|c|c|}
\hline \multirow{3}{*}{$\begin{array}{l}\text { Program } \\
\text { type }\end{array}$} & \multicolumn{12}{|c|}{ Words commonly used in horticulture program titles } \\
\hline & \multicolumn{2}{|c|}{ Design } & \multicolumn{2}{|c|}{ Horticulture $^{\mathrm{z}}$} & \multicolumn{2}{|c|}{ Landscape $^{\mathrm{y}}$} & \multicolumn{2}{|c|}{ Management } & \multicolumn{2}{|c|}{ Technology } & \multicolumn{2}{|c|}{ Turf } \\
\hline & no. & $\overline{\%}$ & no. & $\%$ & no. & $\%$ & no. & $\%$ & no. & $\%$ & no. & $\%$ \\
\hline 4-year & 3 & 1 & 57 & 17 & 45 & 13 & 14 & 4 & 1 & $<1$ & 14 & 4 \\
\hline 2-year & 18 & 5 & 113 & 32 & 58 & 16 & 39 & 11 & 35 & 10 & 22 & 6 \\
\hline Certificate & 46 & 14 & 76 & 23 & 118 & 36 & 72 & 22 & 20 & 6 & 23 & 7 \\
\hline 2 -year & 6 & 3 & 112 & 51 & 35 & 16 & 15 & 7 & 33 & 15 & 9 & 4 \\
\hline Certificate & 42 & 16 & 97 & 37 & 117 & 44 & 49 & 19 & 25 & 9 & 13 & 5 \\
\hline
\end{tabular}

zincludes "horticultural."

"Architecture also was common, but only in the title "landscape architecture."

word "management" and the number of 2-year degrees with the word "design" also decreased between 2012 and 2017. The third most common name for 4-year degree programs was "environmental horticulture" in 2012 and "plant science" in 2017.

While completing the 2017 survey, we identified postsecondary institutions offering horticulture programs that were not included in the 1997 survey. We did this to determine whether new horticulture programs were being created that might offset the decline in institutions identified in the 1997 and 2012 surveys. In 2017, we found 28 institutions offering horticulture that had not been identified in 1997 (Table 5). These institutions offered a total of 67 programs. We wanted to know whether these additional institutions had recently created new programs or whether they had been overlooked in the 1997 survey. We made phone calls and sent e-mail messages to contact representatives of each institution in an attempt to determine when the programs had been created. Using this approach, we were able to verify the status of 20 of these institutions $(69 \%)$. Of these, only two had created new programs since the completion of the 2012 survey. East Mississippi Community College began to offer a 2-year degree in Landscape Management, and Aims Community College began offering 2-year degrees called Environmental Horticulture-Landscape Business and Horticulture Business Management. We also learned that the University of Mount Olive, although not yet counted in these 28 institutions, is in the process of creating new

Table 4. The most common and second-most common horticulture program names for each type of degree in 2012 and 2017, and the frequency of each (in parenthesis).

\begin{tabular}{lll}
\hline Program type & Most common name & Second most common name \\
\hline $\begin{array}{l}\text { 2012 } \\
\text { 4-year }\end{array}$ & Horticulture $(\mathrm{n}=33)^{\mathrm{z}}$ & Landscape architecture $(\mathrm{n}=31)^{\mathrm{y}}$ \\
2 -year & Horticulture $(\mathrm{n}=45)$ & Horticulture technology $(\mathrm{n}=19)$ \\
$\begin{array}{l}\text { Certificate } \\
2017\end{array}$ & Horticulture $(\mathrm{n}=24)$ & Landscape design $(\mathrm{n}=21)$ \\
4 -year & Horticulture $(\mathrm{n}=29)$ & Landscape architecture $(\mathrm{n}=14)^{\mathrm{y}}$ \\
2 -year & Horticulture $(\mathrm{n}=58)$ & Horticulture technology $(\mathrm{n}=25)$ \\
Certificate & Horticulture $(\mathrm{n}=25)$ & Landscape design $(\mathrm{n}=13)^{\mathrm{x}}$ \\
\hline
\end{tabular}

${ }^{\mathrm{z}}$ Horticulture includes the names Horticulture, Horticulture Science(s), General Horticulture, and Horticultural Studies. It does not include any title involving a specific emphasis or aspect of horticulture (e.g., "environmental horticulture" or "horticulture and crop science").

${ }^{y_{T}}$ The third most common name for 4-year degrees in 2012 was Environmental Horticulture, whereas in 2017 it was Plant Science.

"This only counts "landscape design" as a stand-alone title. It does not count landscape design followed by other specializations (e.g., "landscape design and ornamental crops").

Table 5. Number of additional schools with horticulture programs identified in 2017 that were not identified in either the 1997 or 2012 surveys. Of these only two confirmed being created after 2012.

\begin{tabular}{lcc}
\hline Program type & Schools (no.) & Programs (no.) \\
\hline 4-year degree & 3 & 4 \\
2-year degree & 25 & 32 \\
Certificates & 16 & 31 \\
Total & $28^{\mathrm{z}}$ & 67
\end{tabular}

${ }^{\mathrm{z}}$ Some schools offered multiple types of programs (4-year, 2-year, and certificates). Therefore, the sum of schools is greater than the total.

programs that will focus on horticulture and soil science to meet local industry needs (W.D. Phillips, personal communication). All other institutions indicated that their programs existed before 2012, although those we contacted could generally not provide a specific year for program initiation. Therefore, although these 28 institutions add to the total number of postsecondary institutions offering horticulture programs, the minimal number of newly created programs confirms that the overall downward trajectory in horticulture programs is not being offset by the creation of new programs.

Considerably fewer postsecondary U.S. institutions offered horticulture degrees in 2017 compared with 20 years earlier. The loss of 812 -year programs $(38 \%)$ in the 5 -year period between 2012 and 2017 was surprising, particularly in light of a recent report that enrollments for 2-year horticulture degrees between 2004 
and 2012 showed only a slight decline (Reed et al., 2016). Although the number of institutions offering 4 -year horticulture degrees during this same period only declined from 98 to 85 , the fact that the degrees offered by these institutions declined by over $50 \%$ (i.e., 344 to 158 ) illustrates that horticulture programs at 4-year institutions have undergone major and widespread restructuring. Fewer college and university programs, coupled with negative enrollment growth at most of these institutions (Reed et al., 2016), yield fewer horticulture graduates to meet the demand for an educated workforce. As several reports argue, there are already too few students graduating in horticulture to meet industry needs (Bradley et al., 2003; Higgins, 2018; Meyer et al., 2016). One unfortunately held view is that horticulture degrees are unnecessary because they lead to low-wage jobs that may not support an individual's lifestyle (Higgins, 2018; Loose, 2012; Meyer et al., 2016). Because employers are forced increasingly to hire individuals lacking formal horticulture education, the devaluation of a horticulture degree could increase even further.

From the perspective of horticulture programs at 4 -year institutions that recruit transfers from 2 -year programs, the loss of 2-year institutions will contribute to additional declines in enrollment. However, as Reed et al. (2016) concluded, many universities have already adopted admission policies that make it harder for students to transfer from 2-year institutions. In a study of students enrolled in horticulture nearly two decades ago, $46 \%$ had first enrolled in a 2-year horticulture degree and then transferred to a 4-year program, which was greater than the national average for transfer students at that time (Bradley et al., 2000). The decline in 4-year horticulture enrollments reported by Reed et al. (2016) is probably a result, in part, of the decrease in students from 2 -year institutions transferring into their programs.

In 2017, two institutions were identified with new programs that had been created since 2012. One of these (East Mississippi Community College) created a new 2-year landscape management program and attributed their success, in part, to positive relationships with Mississippi
State University: a 4-year institution (W. Arnett, personal communication). The faculty contact at Aims Community College was recently hired and unaware of the specific circumstances surrounding the creation of their two horticulture programs (A. McFarland, personal communication). It may be significant that the horticulture curriculum at Aims Community College is based on Colorado Statewide Articulation Agreements, which allows graduates to transfer to Colorado State University.

We acknowledge that the data presented here cannot predict definitively future trends associated with postsecondary horticulture programs. However, our findings support other recent reports suggesting that horticulture programs at many institutions are facing difficulties. We agree with the conclusions of Higgins (2018) and Meyer et al. (2016) that either a major marketing effort or a major shift in public perception related to horticulture education is needed to reverse the downward trend in postsecondary horticulture programs. We recognize the efforts being made by programs such as Seed Your Future (Seed Your Future, 2018), American Floral Endowment (American Floral Endowment, 2005), and Center for Growing Talent (Produce Marketing Association, 2016) to raise awareness of industry opportunity. This effort is beneficial to bring positive exposure to the horticulture industry as a whole. However, localized action at individual institutions needs to be taken to maximize the benefits of these large-scale efforts.

The downward spiral that culminates with program elimination has many powerful forces that require attention, often simultaneously. Retirement of faculty who acted as strong advocates of programs, loss of fulltime teaching positions, decreased enrollment, shifted or reduced resource allocation, identity loss through program or department mergers, perceived low return on tuition investment, and public perception issues are often correlated if not causally linked. Educators who are trained in and passionate about the horticulture discipline may not be adequately prepared for dealing with the issues presented here and also discussed by others (Higgins, 2018; Meyer et al., 2016; Reed et al., 2016). Nonetheless, failure to discover effective solutions will likely result in continued loss of horticulture programs in the future. Consequently, it may be profitable for faculty and other professionals in the field of horticulture to discover, articulate, and share with each other the specific reasons why some programs are thriving [e.g., institutions showing positive enrollment growth listed in Table 1 of Reed et al. (2016)]. Although each vulnerable horticulture program represents a unique combination of faculty, funding, and institutional climate, an understanding of the best ideas for not only surviving - but thriving —as a program should be pursued actively.

\section{Literature cited}

American Floral Endowment. 2005. American Floral Endowment. 20 Mar. 2018. <https://www.endowment.org/>.

Bradley, J.C., T. Kohlleppel, T.M. Waliczek, and J.M. Zajicek. 2000. Factors affecting recruitment of horticulture students at major universities. HortTechnology 10:631-636.

Bradley, J.C., D. McConnell, M. Kane, and G. Miller. 2003. Development and implementation of a nonmajors horticultural survey class. HortTechnology 13:196-199.

Cappex. 2009. Horticultural science colleges. 18 Dec. 2017. <https://www. cappex.com / colleges / majors / Horticultural-Science-816\#! $\mathrm{p}=1 \&>$.

CollegeSource. 2005. CollegeSource online. 20 Aug. 2018. <https://cso. collegesource.com $/>$.

Higgins, A. 2018. The horticulture industry's age problem is bigger than you think. 5 Aug. 2018. <https://www. washingtonpost.com/lifestyle/home/ the-horticulture-industrys-age-problemis-bigger-than-you-think/2018/08/ $05 / 3 \mathrm{c} 7 \mathrm{~d} 3618-734 \mathrm{f}-11 \mathrm{le} 8-805 \mathrm{c}$ 4 b $67019 \mathrm{fcfe} 4$ story.ht m l? noredirect $=$ on $\&$ utm $m_{-}$term $=$. 8d900d6f5lfe $>$.

Hughes, H.G. 2001. Merged department experience at Colorado State University: How does the addition of an accredited program influence offerings in horticulture. HortTechnology 11:399401.

LaWell, C. 2011. The state of horticulture departments. 20 July 2018. <https:// www.lawnandlandscape.com/article/ 110911-education-horticulture-programsdecline $/>$. 


\section{Research Reports}

Loose, T. 2012. College majors that are useless. 20 July 2018. <https://www. imfjobtraining.org/education.yahoo. net/articles/most_useless_degrees. html>.

Macmillan Reference USA. 1997. College blue book. Macmillan, New York, NY.

Meyer, M.H., D. Needham, J. Dole, B. Trader, J. Fox, M. Conley, M. Neff, and J. Shaw. 2016. Importance of horticulture and perception as a career. HortTechnology 26:114-120.

Miller, B.A. 2011. Marketing and branding the agronomy major at Iowa State
University. J. Nat. Resources Life Sci. Educ. 40(1):1-9.

Produce Marketing Association. 2016. Center for growing talent. 20 Mar. 2018 $<$ https://www.centerforgrowingtalent. $\operatorname{org} />$.

Reed, D.W., M.A. Arnold, R.D. Lineberger, and T.D. Davis. 2016. Challenges of higher education in the U.S.: What will horticulture of the future look like? Acta Hort. 1126:205-218.

Seed Your Future. 2016. Study horticulture. 18 Dec. 2017. <https://www. seedyourfuture.org/study-horticulture/>.
Seed Your Future. 2018. Bloom! 20 Mar. 2018. <https://www.seedyourfuture. org/bloom $>$.

Smith, B. 2014. Don't let your children grow up to be farmers. 9 Aug. 2018. <https://www.nytimes.com/2014/08/ $10 /$ opinion/sunday/dont-let-yourchildren-grow-up-to-be-farmers.html>.

Smith, M.A.L. 2001. The merged department experience at the University of Illinois: Is there strength in numbers? HortTechnology 11:405-408. 